\title{
In silico Determination of Efficiency of Plant Secondary Metabolites to Eradicate Trachoma- A Blinding Keratoconjuctivitis Disease
}

\author{
R. Sathishkumar*, R. Tharani \\ Department of Botany, PSG College of Arts and Science, Coimbatore, India.
}

\author{
ARTICLE INFO \\ Article history: \\ Received on: 15/05/2017 \\ Accepted on: 08/07/2017 \\ Available online: 30/09/2017 \\ Key words: \\ Trachoma, Chlamydia \\ trachomatis, Medicinal \\ Plants, in silico docking \\ analysis, ADME-Toxicity, \\ Ascorbic acid.
}

\begin{abstract}
Objectives: Trachoma is the world's leading, blinding, neglected tropical disease, which is caused by the obligate intracellular bacterium, Chlamydia trachomatis. SAFE strategy, GET-2020 programs and the searching of novel drugs from the natural source are focused to eradicate this ancient infectious disease. The Chlamydial Type III secretion system (T3SS) poses an important mechanism in promoting the chlamydial virulence by mediating the symbiotic relationships. Henceforth, Contact-dependent secretion (Cds) protein, CdsD which has a specific role in the formation of IM ring of the injectisome, was considered and targeted to interrupt the pathogenic development of the organism.
\end{abstract}

Materials and Methods : The compounds from the plants Tribulus terrestris, Azadirachta indica, Ziziphus mucronata, Erythrina indica and Jatropha curcas were analyzed using the molecular docking studies ADMEproperties, drug-likeness using the Schrodinger software.

Results: The study revealed the significant interactions of the compounds protodioscin, rutin, ascorbic acid, quercetin, stearic and oleic acid, genistein, alpinumisoflavone and vanillin. Among, ascorbic acid or vitamin C has interacted with the residue Glu626 and other active site residues, whereas, the ADME-properties predicted were also noteworthy. Apart from, the compounds also had interaction with the important residue Gly659 of the protein. These residues Glu626 and Gly659 were conserved in the protein and also have structural importance.

Conclusion: The compound ascorbic acid had significant interaction with the target protein, could be further analyzed for stability using molecular dynamics study and in vitro. Being a dietary supplement, the compound could be prepared in any form of formulation.

\section{INTRODUCTION}

Trachoma is the world's leading blinding keratoconjuctivitis disease caused by the obligate intracellular bacterium called Chlamydia trachomatis. The infection spread through direct contact with an infected person as well as indirect contact with clothing or flies which have in contact with the infected person. Due to poor sanitation, crowded living condition, the disease has the opportunity to recur and since due

\footnotetext{
* Corresponding Author

Dr. R. Sathishkumar, Assistant Professor, Department of Botany, PSG College of Arts and Science, Coimbatore - 641 014, India. Mobile Number: + 919894161756

E.mail: sathishbioinf @ gmail.com
}

to the continuous infections which revokes the immune system and results in the deposition of follicular bodies in the conjunctiva of the eye. This on time being leads to conjunctival scarring and distorts the upper tarsal plate causing entropion and trichiasis (Gambhir et $a l ., 2009)$. The end result of the infection includes corneal abrasions, corneal scarring, opacification and ultimately blindness. World Health Organizations put forth the SAFE (Surgery, Antibiotics, Facial Cleanliness and Environmental improvement) strategy as a preventable measure, along with, Pfizer Ltd. donated the zithromax (contains azithromycin) to eradicate the infections (Stocks et al., 2014). However, the infection prevails endemic in few areas. It has been scientifically observed that use of azithromycin is effective than the tetracycline. The humoral immune response was observed lacking where the anti-chlamydial antibodies have been found in the tears and serum of clinically active patients. 
According to WHO, most of the developing and developed countries rely on the herbal based products due to its safety and its medicinal ability, the current study postulates to observe the efficiency of the plant secondary molecules from Tribulus terrestris, Azadirachta indica, Ziziphus mucronata, Erythrina indica and Jatropha curcas.

The organism has biphasic life cycle called highly infectious elemental body (EB) and metabolically active reticular body ( $\mathrm{RB})$, where the former is environmentally stable, the latter is liable (Guerra et al., 2016). Being an obligate intracellular pathogen, the Chlamydiales are clever to manage and manipulate the host cell biology for its successful pathogenesis. Type III secretion system (T3SS) is an important mechanism in promoting the chlamydial virulence, where this system in particular was found to exist in most of the Gram-negative pathogens and aid in virulence by mediating the symbiotic relationships (He et al., 2004). T3SS is composed of several structural proteins, forms the secretion needle which act like molecular syringe to pass the antihost bacterial "effector" proteins (Betts-Hampikian and Fields, 2010). T3SS assembly, structure, function and its regulation are exclusively reviewed by Deng et al. (2017). T3SS is said to contain three cellular membranes, the bacterial inner membrane, the outer membrane and eukaryotic host cell membrane (Deng et al., 2017). The general function of T3SS includes host immune responses, cytoskeletal dynamics, vesicle transport and signal transduction pathways (Buttner, 2012). In the case of Chlamydia spp. T3SS is used for differentiate, replicate and disseminate (Beeckman and Vanromapay, 2010), where recently chlamydial protease-like activity factor (CPAF), a conserved serine protease secreted in the infected host cell exhibits the host immune evasion by inhibiting the p65 nuclear translocation (Patton et al., 2016). It is defined that T3SS has three major structural components 1) Basal body which spans the periplasmic space between the IM and the OM of the bacteria, 2) the injection needle, spanning from basal body towards the eukaryotic host cell, 3) the cytoplasmic part. Contact-dependent secretion (Cds) protein occupies the basal body, where the IM ring especially made of two concentric rings (an inner CdsJ and outer CdsD) which interacts each other (Bergeron et al., 2013). The protein targeted in the present study is CdsD, which has 829 aminoacids and has a transmembrane domain (530-551 residues), a C-terminal periplasmic part and $\mathrm{N}$ terminal cytosolic part. Since, this CdsD takes part in the formation of outer ring structure of the IM-ring injectisome, this protein is considered significant to target in order to interrupt the pathogenic development of the organism, C. trachomatis (McShan and Guzman, 2015). Moreover, CdsD has a unique N-terminus containing FHA domain which undergoes phosphorylation and capable to interact with the novel subset of inner membrane proteins (Betts-Hampikian and Fields, 2010).

\section{MATERIALS AND METHODS}

The 3D structure of CdsD protein of Chlamydial T3SS was retrieved from the $\mathrm{PDB}$ of corresponding ID: 4QQ0 (http://www.rcsb.org/pdb/home/home.do). The active site pocket for the protein was predicted using LigSite, an online tool available at http://projects.biotec.tu-dresden.de/pocket/. The plant molecules are retrieved from the PubChem database, a database specifically for small molecules. The ADME properties were analyzed for the compounds to test its drug-likeness using QikProp, a Schrodinger module. Finally, the potential of compounds to interact with the protein $\mathrm{CdsD}$ was carried out using Glide module and hydrogen bond formations were observed using PyMol software.

\section{RESULTS AND DISCUSSION}

The binding efficiency with the protein CdsD, G. score, residues interacting and its bond length were tabulated (Table 1). The least G. score was observed for the compound protodioscin which had $-6.15 \mathrm{Kcal} / \mathrm{mol}$, followed by rutin, ascorbic acid and quercetin, where the G. score are $-4.66,-4.63$ and $-4.18 \mathrm{Kcal} / \mathrm{mol}$. All these compounds formed 4 hydrogen bonds. Protodioscin from Tribulus terrestris had interaction with the active site residues Glu651 and Pro650 of bond length 1.6 and $2.3 \AA$, respectively, where the other two bonds were with Lys687 (1.9 ̊) and Asp685

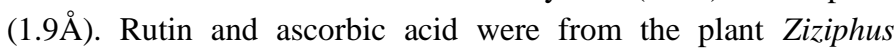
mucronata, each interacted with the residues Trp629, Glu626, Arg597 and Asn598. Quercetin from Azadirachta indica had interaction with Asn598 (2.4 ̊), Glu626 (1.8 ̊), Trp269 (2.1 $)$ and $\operatorname{Arg} 597$ (2.4 $\AA$ ), where the active site residues are Arg597 and Glu626. Among the active site residues predicted, the following were the residues had interaction with the plant compounds, they are Arg597, Ser649, Pro650, Trp629, Asn598, Glu651, Glu626 and Gly659. Most of the compounds such as quercetin, berberine hydrogen sulphate, arachidic acid, terrestribisamide, vanillin and rutin interacted with Arg597. The residue Gly659 is conserved in $\mathrm{CdsD}$ protein which is located in the $\beta 2$ of $\alpha \beta \beta \alpha \beta$ strands and observed to interact with stearic acid of Jatropha curcas and oleic acid of Erythrina indica. Since these fatty acids binding to the residue Gly659 is conserved in $\mathrm{CdsD}$, the interaction might have its own significance, however, the following importance of fatty acids are also be the evidence. The stearic and oleic acids are reported to be rich in the plant Strychnos cocculoides, which has been used to treat trachoma by Nkoya in Zambia (Anonymous, 1996). A patent has been filed for the product developed based on the plant derived seed extracts which are rich in essential fatty acids including stearic acid and oleic acid that could be used to treat various ailments including trachoma (US Patent No. 8586104). The residue Glu626 is reported to be involved in the PD1-PD1 interactions through salt bridges, in the present study, the compounds such as quercetin, genistein, alpinumisoflavone, vanillin, rutin and ascorbic acid showed interaction with this residue. This might play vital role in disrupting the assembly of the T3SS. Moreover, quercetin, a bioflavanoid well known for its role as antioxidant and also for several medicinal properties, has been reported for inclusion formation in the chlamydial EB's (Alvesalo et al., 2006). 
Table 1: Interactions of Plant Compounds with CdsD of Chlamydial T3SS.

\begin{tabular}{|c|c|c|c|c|}
\hline NAME OF THE LIGAND & $\begin{array}{c}\text { RESIDUES } \\
\text { INTERACTED }\end{array}$ & BOND LENGTH & $\begin{array}{l}\text { NO. OF BONDS } \\
\text { FORMED }\end{array}$ & $\begin{array}{l}\text { G. SCORE } \\
\text { (Kcal/mol) }\end{array}$ \\
\hline \multicolumn{5}{|c|}{ Azadirachta indica } \\
\hline \multirow{4}{*}{ Quercetin (5280343) } & ASN-598(H-O) & 2.4 & \multirow{4}{*}{4} & \multirow{4}{*}{-4.18} \\
\hline & GLU-626(O-H) & 1.8 & & \\
\hline & TRP-269(O-H) & 2.1 & & \\
\hline & ARG-597(O-H) & 2.4 & & \\
\hline \multirow{4}{*}{ Azadirachtin (5281303) } & LYS-687 (O-H) & 1.6 & \multirow{4}{*}{4} & \multirow{4}{*}{-3.64} \\
\hline & LYS-687 (H-O) & 2 & & \\
\hline & ARG-747 (H-O) & 2 & & \\
\hline & ARG-747 (H-O) & 2.6 & & \\
\hline$\beta$-Sitosterol (222284) & SER-658(H-O) & 1.8 & 1 & -0.79 \\
\hline \multicolumn{5}{|c|}{ Berberis aquifolium } \\
\hline \multirow{2}{*}{ Berberine hydrogen sulphate (12457) } & ARG-597(H-O) & 2.2 & \multirow[b]{2}{*}{2} & \multirow[b]{2}{*}{-2.47} \\
\hline & ARG-597(H-O) & 1.9 & & \\
\hline \multicolumn{5}{|c|}{ Erythrina indica } \\
\hline Oleic acid (445639) & GLY-659(H-O) & 1.8 & 1 & -1.08 \\
\hline \multirow{3}{*}{ Erythrodiol (101761) } & LEU-684(O-H) & 1.9 & \multirow{3}{*}{3} & \multirow{3}{*}{-2.32} \\
\hline & ASP-685(O-H) & 1.6 & & \\
\hline & LYS-687(H-O) & 1.9 & & \\
\hline Stigmasterol (5280794) & $\mathrm{PRO}-650(\mathrm{O}-\mathrm{H})$ & 2 & 1 & -0.43 \\
\hline \multirow{2}{*}{ Genistein(5280961) } & ASN-598(H-O) & 1.9 & \multirow{2}{*}{2} & \multirow{2}{*}{-2.25} \\
\hline & GLU-626(O-H) & 1.6 & & \\
\hline & ASN-598(H-O) & 1.9 & & \\
\hline Alpinumisoflavone (5490139) & GLU-626(O-H) & 1.6 & 2 & -2.65 \\
\hline & Jatropa c & & & \\
\hline & ARG-597(H-O) & 1.6 & & \\
\hline Arachidic acid (10467) & ARG-597(O-H) & 1.8 & 2 & -2.06 \\
\hline Cetyl Palmitate (10889) & LYS-687(O-H) & 2.5 & 1 & -2.11 \\
\hline Stearic acid (5281) & GLY-659(H-O) & 1.8 & 1 & -1.46 \\
\hline & ASN-686(H-O) & 2.2 & & \\
\hline Oleanolic acid (10494) & VAL-688(O-H) & 2 & 2 & -1.61 \\
\hline Linoleic acid (5280450) & ARG747(H-O) & 2 & 1 & -0.22 \\
\hline & Tribulus te & & & \\
\hline Hecogenin (91453) & SER-658(H-O) & 2 & 1 & -0.67 \\
\hline & SER-658(O-H) & 2.7 & & \\
\hline Terrestribisamide (5321825) & ARG-597(H-O) & 2.5 & 3 & -3.65 \\
\hline & ASN-598(H-O) & 2 & & \\
\hline & LYS-687(H-O) & 1.9 & & \\
\hline & ASP-685(O-H) & 1.9 & & \\
\hline Protodioscin (441891) & GLU-651(O-H) & 1.6 & 4 & -6.15 \\
\hline & PRO-650(O-H) & 2.3 & & \\
\hline & ASN-598(O-H) & 2 & & \\
\hline & ARG-597(O-H) & 2.4 & & \\
\hline Vanillin (1183) & GLU-626(H-O) & 1.7 & 4 & -3.41 \\
\hline & SER-649(O-H) & 2.4 & & \\
\hline & Ziziphus mu & & & \\
\hline Butylated hydroxyl toluene (31404) & ARG-747(H-O) & 2.3 & 1 & -0.94 \\
\hline Mucronine (5281593) & LYS-687 (O-H) & 2.1 & 1 & -1.47 \\
\hline & TRP-629(H-O) & 2.3 & & \\
\hline & GLU-626(O-H) & 1.7 & & \\
\hline Rutin (5280805) & ARG-597(O-H) & 2.3 & 4 & -4.66 \\
\hline & ASN-598(H-O) & 2.3 & & \\
\hline & TRP-629(H-O) & 2.3 & & \\
\hline & GLU-626(O-H) & 1.7 & & \\
\hline Ascorbic acid (54670067) & ASN-597(O-H) & 2.3 & 4 & -4.63 \\
\hline & ARG-598(H-O) & 2.2 & & \\
\hline & SER -658 (H-O) & 2.6 & & \\
\hline Gallic Acid (370) & SER -658 (H-O) & 2 & 2 & -3.12 \\
\hline
\end{tabular}

Rutin contains four enr also been reported for moderate effect in the ocular blood flow (Majumdar and Srirangam, 2010). Genistein had antichlamydial effect against both $C$. trachomatis and $C$. pneumonia and the IC50 was ranged between 12 to $>100$ $\mu \mathrm{M}$ (Brown et al., 2016). Biochanin A, an isoflavone component at the concentration of $25 \mu \mathrm{M}$ had significantly reduced the chlamydial inclusion size and also the inclusion counts in then C. trachomatis infected cell cultures, which even prevented the formation of new infectious progeny (Hanski et al., 2014). Alpinumisoflavone is also a type of isoflavone might also to possess similar effect which could be identified on further in vitro observation. Elderly populations are highly prone to age-related 
muscular degeneration, trachoma, other infectious and parasitic diseases in most of the cataract cases, however, vitamin $\mathrm{C}$ or ascorbic acid intake in the diet as a routine basis has been proved to lower the risk of cataract (Rautiainen et al., 2010). In the present study, ascorbic acid had least G.score value as well as significant interaction. The interactions of ascorbic acid with CdsD protein of Chlamydial T3SS was shown in the fig. 1. Polyphenols is the most abundantly found secondary metabolites to be present in the plants which are synthesized during the adverse condition or during infections in the plants (Potroz and Cho, 2015). So far, the exact mechanism of antichlamydial activity of polyphenols are not known, however, in the present study, vanillin, a polyphenol was observed to interact with the Glu626 residue, which has role in the salt bridge formation of the protein CdsD.

The ADME properties of the plant compounds were predicted and compared to the standard range as per the chart of
QikProp module of Schrodinger software (Table 2). The compound such as arachidic acid, $\beta$-sitosterol, cetyl palmitate, mucornine, protodioscin, rutin and stigmasterol has violated the ADME properties. Among the compounds, discussed earlier for its significant interaction and G.score, also observed in violating the drug-likeness rules, where the compound protodioscin (-6.15 $\mathrm{Kcal} / \mathrm{mol}$ ) showed higher range of molecular weight and number of hydrogen donor-acceptor. The compound rutin has slightly higher hydrogen acceptor and $\log \mathrm{P}$ value as well as the molecular weight is observed to be $610.524 \mathrm{KDa}$. Other compounds like ascorbic acid, quercetin, genistein, oleic acid, stearic acid, vanillin and alpinumisoflavone are predicted with significant ADMEproperties. Apart from the Lipinkis's rule of five, other important factors like Jorgensen rule of 3, number of rotatable bonds, SASA properties, dipole moment, blood/brain barrier, oral absorption were also been predicted.

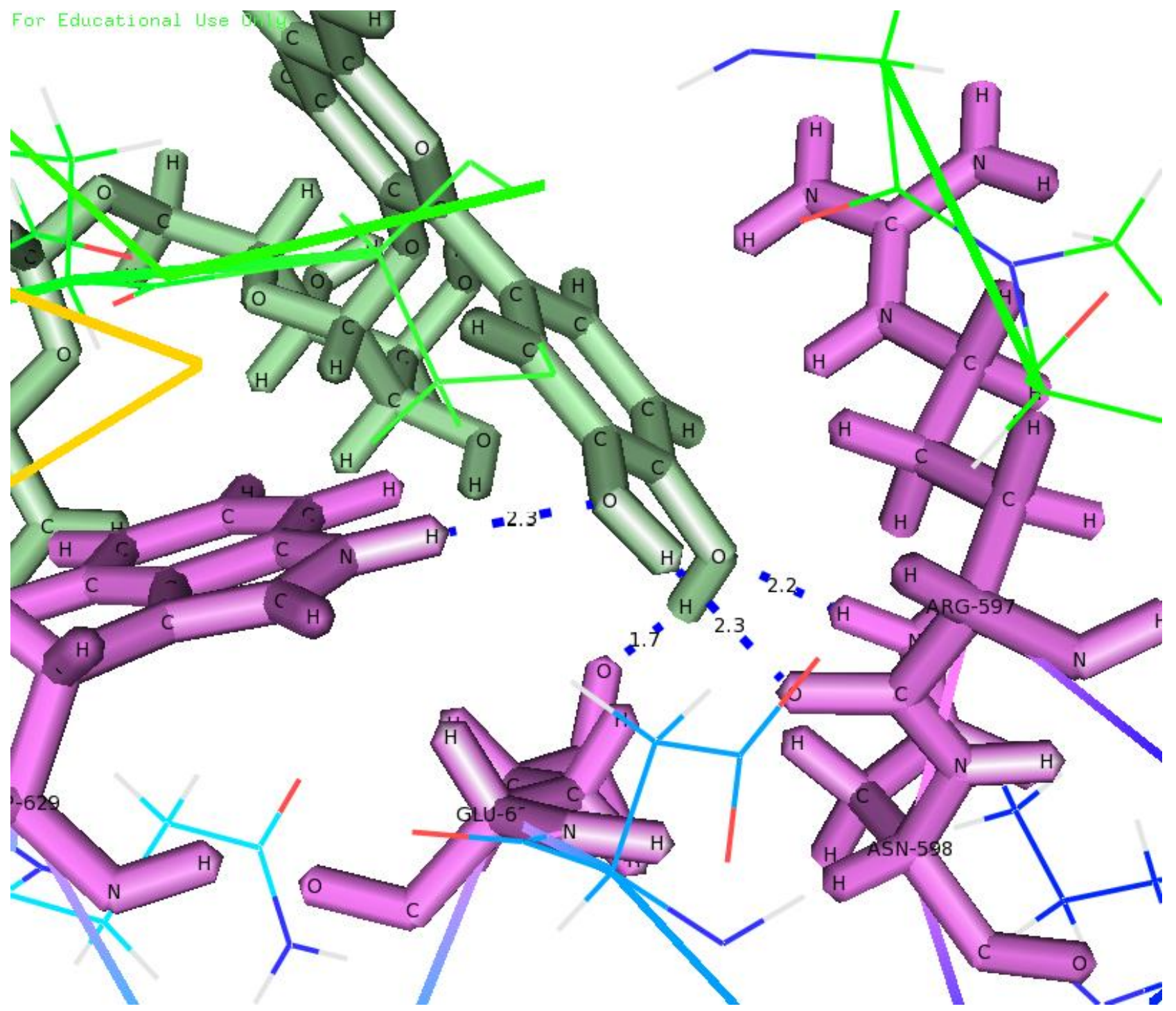

Fig.1: Interaction of Ascorbic acid with CdsD protein of Chlamydial T3SS

Note: Cyanide Green color indicates the ligand molecule and pink color indicates the protein; Blue dotted line indicates the bond formation. 
Table 2: ADME Properties of Plant Compounds.

\begin{tabular}{|c|c|c|c|c|c|c|c|}
\hline Molecule & $\begin{array}{c}\text { Molecular } \\
\text { Weight }\end{array}$ & $\begin{array}{l}\text { No. of Rotatable } \\
\text { Bonds }\end{array}$ & $\begin{array}{c}\text { Dipole } \\
\text { Moment }\end{array}$ & SASA & $\begin{array}{l}\text { Donor - } \\
\text { Hydrogen } \\
\text { Bonds }\end{array}$ & $\begin{array}{l}\text { Acceptor - } \\
\text { Hydrogen } \\
\text { Bonds }\end{array}$ & $\begin{array}{l}\text { QP } \log P \text { for } \\
\text { water/gas }\end{array}$ \\
\hline Normal Range & $130.0 / 725.0$ & $0.0 / 15.0$ & $1.0 / 12.5$ & $300.0 / 1000.0$ & $0.0 / 6.0$ & $2.0 / 20.0$ & $4.0 / 45.0$ \\
\hline Alpinumisoflavone & 336.343 & 3 & 2.863 & 586.99 & 1 & 3.75 & 8.592 \\
\hline Arachidic acid & 312.535 & 18 & 5.843 & 808.907 & 1 & 2 & 1.861 \\
\hline Ascorbic acid & 176.126 & 6 & 6.366 & 337.875 & 4 & 7.9 & 14.617 \\
\hline Azadirachtin & 720.723 & 8 & 3.175 & 825.544 & 2 & 18.05 & 22.509 \\
\hline$\beta$-Sitosterol & 414.713 & 7 & 1.821 & 750.211 & 1 & 1.7 & 3.651 \\
\hline Butylated hydroxyl toluene & 220.354 & 3 & 1.803 & 497.423 & 1 & 0.75 & 2.724 \\
\hline Cetyl Palmitate & 480.856 & 29 & 2.778 & 1233.18 & 0 & 2 & -1.357 \\
\hline Erythrodiol & 442.724 & 3 & 3.489 & 691.826 & 2 & 3.4 & 7.528 \\
\hline Gallic Acid & 170.121 & 4 & 5.716 & 342.418 & 4 & 4.25 & 12.035 \\
\hline Genistein & 270.241 & 4 & 4.524 & 480.841 & 2 & 3.75 & 9.888 \\
\hline Hecogenin & 430.626 & 1 & 2.887 & 699.694 & 1 & 5.2 & 8.291 \\
\hline Linoleic acid & 280.45 & 14 & 5.895 & 615.977 & 1 & 2 & 2.579 \\
\hline Mucronine & 492.617 & 6 & 13.393 & 741.943 & 2.5 & 8.25 & 17.736 \\
\hline Oleanolic acid & 456.707 & 2 & 6.318 & 697.577 & 2 & 3.7 & 8.335 \\
\hline Oleic acid & 282.465 & 15 & 6.013 & 731.282 & 1 & 2 & 2.46 \\
\hline Protodioscin & 1049.211 & 27 & 13.277 & 1410.99 & 13 & 35.5 & 54.415 \\
\hline Quercetin & 302.24 & 5 & 3.533 & 512.235 & 4 & 5.25 & 14.363 \\
\hline Rutin & 610.524 & 15 & 7.814 & 782.813 & 9 & 20.55 & 35.709 \\
\hline Stearic acid & 284.481 & 16 & 5.843 & 742.866 & 1 & 2 & 2.143 \\
\hline Stigmasterol & 412.698 & 6 & 2.146 & 756.97 & 1 & 1.7 & 3.917 \\
\hline Terrestribisamide & 440.495 & 15 & 8.849 & 850.024 & 4 & 8 & 15.441 \\
\hline Vanillin & 152.149 & 3 & 4.986 & 353.728 & 1 & 3.5 & 6.477 \\
\hline
\end{tabular}

\begin{tabular}{|c|c|c|c|c|c|c|}
\hline Molecule & $\begin{array}{l}\text { QP } \log P \text { for } \\
\text { octanol } \\
\text { /water }\end{array}$ & $\begin{array}{l}\text { QP } \log \text { BB for } \\
\text { brain / blood }\end{array}$ & $\begin{array}{c}\text { No. of } \\
\text { Primary } \\
\text { Metabolites }\end{array}$ & $\begin{array}{c}\text { \% Human Oral Absorption in } \\
\text { GI }(+-20 \%)\end{array}$ & $\begin{array}{c}\text { Lipinski } \\
\text { Rule of } 5 \\
\text { Violations }\end{array}$ & $\begin{array}{c}\text { Jorgensen } \\
\text { Rule of } 3 \\
\text { Violations }\end{array}$ \\
\hline Normal Range & $-2.0 / 6.5$ & $-3.0 / 1.2$ & $1.0 / 8.0$ & $<25 \%$ is poor $)(>80 \%$ is high) & Max. 4 & Max. 3 \\
\hline Alpinumisoflavone & 3.64 & -0.792 & 2 & 100 & 0 & 0 \\
\hline Arachidic acid & 6.852 & -1.837 & 1 & 96.71 & 1 & 1 \\
\hline Ascorbic acid & -1.852 & -1.703 & 5 & 44.988 & 0 & 0 \\
\hline Azadirachtin & 1.769 & -1.571 & 5 & 51.569 & 2 & 0 \\
\hline$\beta$-Sitosterol & 7.435 & -0.336 & 3 & 100 & 1 & 1 \\
\hline Butylated hydroxyl toluene & 4.336 & 0.303 & 4 & 100 & 0 & 0 \\
\hline Cetyl Palmitate & 11.83 & -2.075 & 1 & 100 & 1 & 1 \\
\hline Erythrodiol & 6.08 & -0.124 & 4 & 100 & 1 & 1 \\
\hline Gallic Acid & -0.569 & -1.667 & 3 & 41.486 & 0 & 1 \\
\hline Genistein & 1.678 & -1.316 & 3 & 76.537 & 0 & 0 \\
\hline Hecogenin & 5.042 & -0.217 & 2 & 100 & 1 & 1 \\
\hline Linoleic acid & 5.343 & -1.2 & 4 & 89.406 & 1 & 0 \\
\hline Mucronine & 3.019 & -0.13 & 7 & 85.381 & 0 & 1 \\
\hline Oleanolic acid & 6.237 & -0.434 & 3 & 94.478 & 1 & 1 \\
\hline Oleic acid & 5.966 & -1.583 & 3 & 91.522 & 1 & 1 \\
\hline Protodioscin & -1.912 & -7.17 & 14 & 0 & 3 & 2 \\
\hline Quercetin & 0.387 & -2.309 & 5 & 52.9 & 0 & 1 \\
\hline Rutin & -2.392 & -4.285 & 10 & 0 & 3 & 2 \\
\hline Stearic acid & 6.071 & -1.656 & 1 & 92.136 & 1 & 1 \\
\hline Stigmasterol & 7.479 & -0.282 & 5 & 100 & 1 & 1 \\
\hline Terrestribisamide & 3.543 & -2.838 & 4 & 84.805 & 0 & 1 \\
\hline Vanillin & 1.005 & -0.656 & 2 & 82.043 & 0 & 0 \\
\hline
\end{tabular}

\section{CONCLUSION}

The compound ascorbic acid, a dietary supplement has significantly interacted with the active site residue Glu626, which is a conserved amino acid residue of the protein and has structural importance. The compound exhibited significant G.score as well as the predicted ADME-properties and drug-likeness were also noteworthy. Therefore, the compound should further be analyzed for the stability in the interaction with the targeted CdsD protein using molecular dynamics studies. As well as the toxicity of the molecules are also be predicted, therefore, to determine its efficiency in vitro.

Financial support and sponsorship: Nil.

Conflict of interest: The authors declare no conflict of interest. 


\section{REFERENCES}

Alvesalo J, Vuorela H, Tammela P, Leinonen M, Saikkum P, Vuorela P. Inhibitory effect of dietary phenolic compounds on Chlamydia pneumonia in cell cultures. Biochem Pharmacol, 2006; 71: 735-741.

Available at https://www.google.com/patents/US9610313

(Accessed 11 June 2017)

Beeckman DS, Vanrompay DC. Bacterial secretion systems with an emphasis on the chlamydial type III secretion system. Curr Issues Mol Biol, 2010; 12: 17-41.

Bergeron JR, Worrall LJ, Sgourakis NG, Dimaio F, Pfuetzner RA, Felise HB, Vuckovic M, Yu AC, Miller SI, Baker D, Strynadka NC. A refined model of the prototypical Salmonella SPI-1 T3SS basal body reveals the molecular basis for its assembly. PLOS Pathog, 2013; 9: e1003307.

Betts-Hampikian HJ, Fields KA. The chlamydial type III secretion mechanism revealing cracks in a tough nut. Frontiers in Microbiology, 2010; 1: 1-13.

Brown MA, Potroz MG, Teh SW, Cho NJ. Natural products for the treatment of Chlamydiaceae infections. Microorganisms, 2016; 4(39): $1-30$.

Buttner D. Protein export according to schedule: architecture, assembly, and regulation of type III secretion systems from plant- and animal- pathogenic bacteria. Microbiol Mol Biol Rev, 2012; 76: 262-310.

Deng W, Marshall NC, Rowland JL, McCoy JM, Worrall LJ, Santos AS, Strynadka NC, Finlay BB. Assembly, structure, function and regulation of type III secretion systems. Nature Reviews, 2017; 15: 323 337.

Hans Dieter Neuwinger, 1996. African Ethnobotany: poisons and drugs: Chemistry, pharmacology, toxicology, Chapman \& Hall, pp. 593.
Hanski L, Genina N, Uvell H, Malinovskaja K, Gylfe A, Laaksonen T, Kolakovic R, Makila E, Salonen J, Hirvonen J. Inhibitory activity of the isoflavone biochanin a on intracellular bacteria of genus Chlamydia and initial development of a buccal formulation. PLoS ONE, 2014; 9: e115115.

Majumdar S, Srirangam R. Potential of the bioflavonoids in the prevention/treatment of ocular disorders. J Pharm Pharmacol, 2010; 62(8): 951-965

McShan AC, Guzman RN. The bacterial type III secretion system as a target for developing new antibiotics. Chem Biol Drug Des, 2015; 85: 30-42.

Patton MJ, McCorrister S, Grant C, Westmacott G, Fariss R, Hu P, Zhao K, Blake M, Whitmire B, Yang C, Caldwell HD, McClarty G. Chlamydial protease-like activity factor and type III secreted effectors cooperate in inhibition of p65 nuclear translocation. American Society of Microbiology, 2016; 7(5): 1-9.

Rautiainen S, Lindblad BE, Morgenstern R, Wolk A. Vitamin C supplements and the risk of age-related cataract: a population-based prospective cohort study in women. Am J Clin Nutr, 2010; 91(2): 487-493.

\section{How to cite this article:}

Sathishkumar R, Tharani R. In silico Determination of Efficiency of Plant Secondary Metabolites to Eradicate Trachoma- A Blinding Keratoconjuctivitis Disease. J App Pharm Sci, 2017; 7 (09): 116121 